\title{
TERRITORIAL BEHAVIOR OF EASTERN CHIPMUNKS (TAMIAS STRIATUS): ENCOUNTER AVOIDANCE AND SPATIAL TIME-SHARING ${ }^{1}$
}

\author{
Thomas GeTTY \\ Division of Biological Sciences, University of Michigan, Ann Arbor, Michigan 48109 USA
}

\begin{abstract}
The structure and dynamics of chipmunk home ranges were characterized by focalanimal observation. Neighboring animals were territorial, but their home ranges overlapped extensively and did not have exclusive core areas. Established neighbors avoided encountering each other. Their pattern of encounter avoidance with extensive spatial overlap resulted in spatial time-sharing. Territorial interference with the timing of space-use did not affect the total utilization of shared areas within a resident's home range. Distance and patch structure were important proximate determinants of space-use intensity. The results suggest that territorial interference is more important as a mechanism for deterring the immigration of nonneighbors than as a continuously operative competitive mechanism between established neighbors. The concept that the proximate object of interference competition is access to space is questioned.
\end{abstract}

Key words: avoidance; behavioral ecology; central-place; competition; interference; microhabitat; Tamias striatus.

\section{INTRODUCTION}

Aggression is probably the most studied mechanism of animal behavior, due, in part, to the spectacular nature of many aggressive acts. Territorial aggression is one mechanism of resource competition, i.e., interfering with access to space and the resources therein (Miller 1967, Tinnin 1972). Interference is assumed to reduce exploitation competition, and free resources that more than compensate for the costs of interfering (Case and Gilpin 1974). However, the relationship between aggression and access to space is not a simple one, since it involves long-term establishment patterns, as well as ongoing relationships between established neighbors.

Burt (1940) observed of a territorial chipmunk: "Although other chipmunks often invaded her territory, she invariably drove them away (if she happened to be present at the time)." Dunford (1970) commented that when he placed trays of seeds in chipmunk territories to elicit aggressive encounters, intruding neighbors routinely gained access to these easily defended resources by simply watching until the resident moved away from the area (to cache items, for instance). This raises the interesting question of whether interference with "when" neighbors exploit a resident's territory affects "how much" it is exploited; that is, does interference with the timing of access to space (and hence resources) affect the total access? Exploitation or interference competition should be evident in individual space utilization patterns. This study tests the null hypothesis that neighboring territorial chipmunks have no impact on each other's space utilization patterns. Both the timing and the total intensity of utilization are examined.

Social influences on space-use are complicated by

${ }^{1}$ Manuscript received 3 March 1980; revised and accepted 9 October 1980. ecological factors. Chipmunk home ranges are exploited from a central den or nearby perch, and they are superimposed on a patchy habitat, as well as on each other. Linear and nonlinear regression models are used to examine how resident use intensity is influenced by vegetative structure, distance from the center of activity, and neighbor use intensity.

\section{METHODS \\ Study site}

This work was carried out between June 1976 and August 1978 in the Southwest Woods of the E. S. George Reserve, Livingston County, Michigan. The study site occupies approximately 2 ha of a mature woods dominated by oaks and hickories, bordered on the south by an old field, and sloping eastward to a marsh (Fig. 1). An unimproved, rarely used access road traverses the site, which was divided into a grid of $5 \times 5 \mathrm{~m}$ quadrats by numbered stake-wire flags.

\section{Vegetation analysis}

In September 1977, an exhaustive survey of vegetational composition was carried out in 228 quadrats (Zenker 1978). Percent cover of all herbs and shrubs (estimated Braun-Blanquet cover classes), number of trees by species and size class (dbh), and lengths of logs were analyzed by cluster analysis in order to group quadrats into patch types (c.f. DeGhett 1974). Since there is no a priori "proper" choice among clustering methodologies, the results of such niche-dimension analyses can only be presented as an hypothesis to be tested. The patch structure presented here (Fig. 1) was abstracted from the similar results of several weighting and linkage schemes. Clusters (patch types) correspond to visibly distinct vegetational structure. An additional 148 peripheral unsurveyed quadrats were then assigned to patch types based on spatial and visual affinity to surveyed quadrats. 
VEGETATION PATCH STRUCTURE

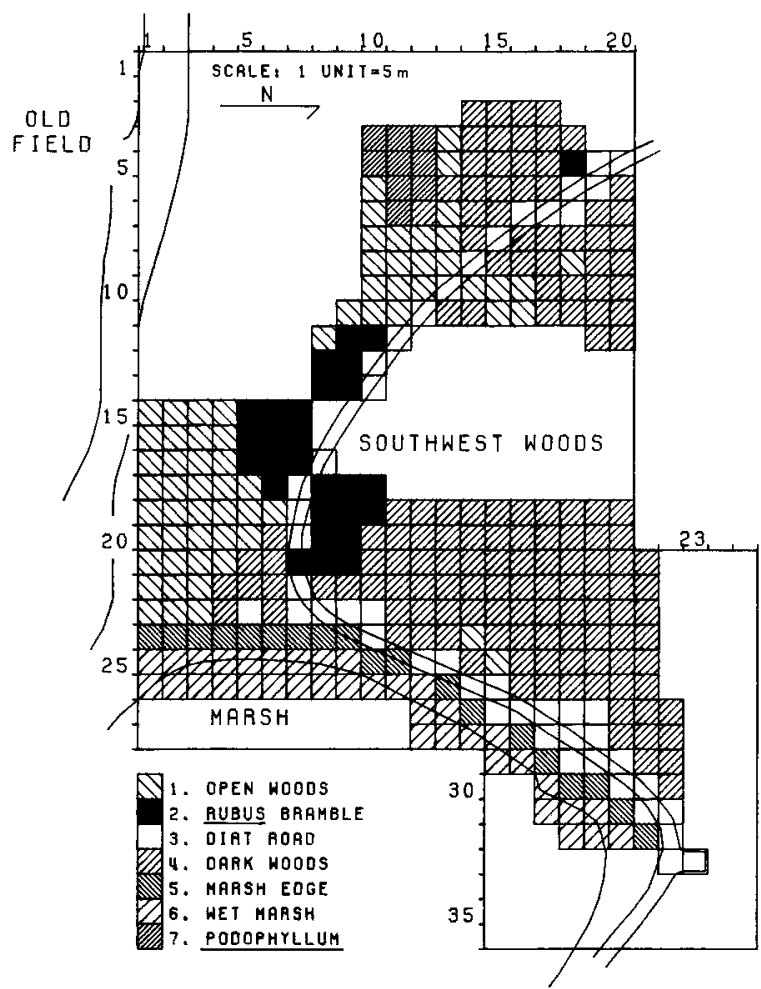

Fig. 1. The study area, at the southeast corner of the Southwest Woods of the George Reserve. Shaded quadrats show the patch structure: (1) open (sedge) woods, (2) blackberry bramble, (3) dirt road, (4) darker (brushy) woods, (5) marsh edge, (6) wet marsh, (7) mayapple patch.

\section{Trapping}

Distribution of traps ( 90 , baited with peanut butter and rolled oats) and effort was irregular, and both were adjusted as necessary to maximize capture success. All animals were weighed, sexed, and permanently marked by toe clipping, ear punching, or ear tagging. Field identification was made by the use of black dye spots (Lady Clairol hair dye) along the stripes.

\section{Observation}

Data were collected in the summer (June-August) and fall (September-November) of 1977. The observations were divided into summer and fall seasons to correspond to the periods before and after the familiar August "lull" in activity (Yahner 1977). The lull coincides with a period of transition in diet as the availability of food items changes (Wrazen 1976). Six scaffolding towers were arranged at the edges of areas of most intense activity (Fig. 2). When the observer sat quietly on these, the impact on chipmunk behavior seemed negligible. A digital microprocessor (KIM 1/ KIM 2, Moss Technology) was adapted and programmed to function as a battery-powered event re-

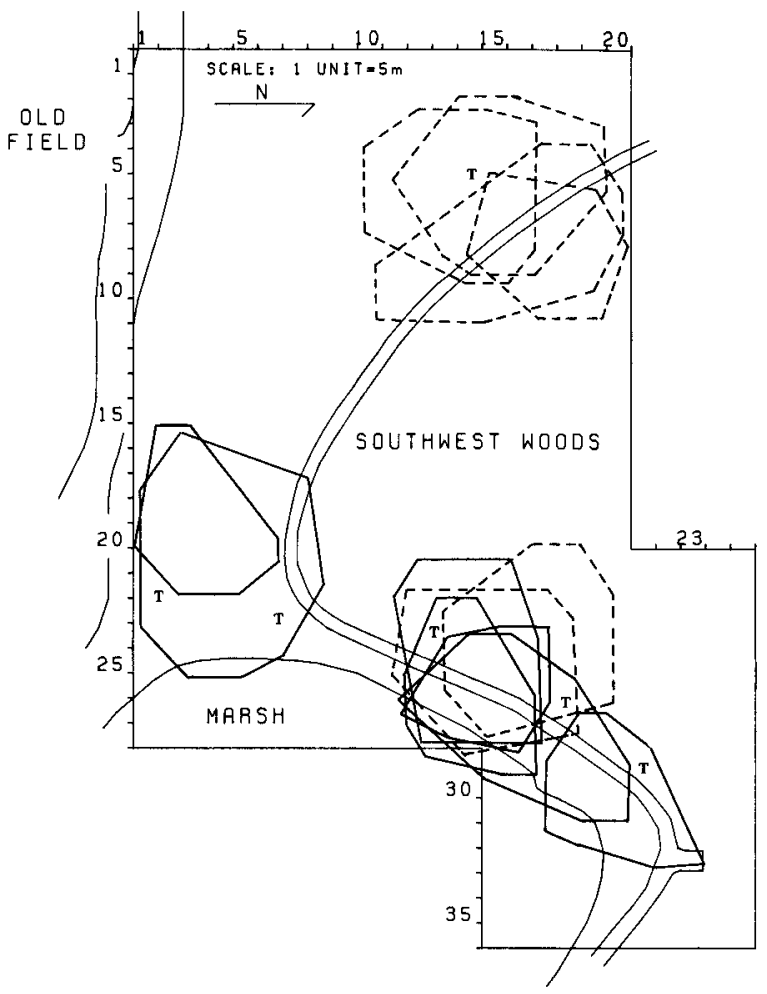

FIG. 2. Home range boundaries of summer (solid) and fall (dashed) study animals. Each $T$ marks the location of a semipermanent observation tower.

corder. Events ("who, what, where, and with whom") could be recorded to the nearest $0.2 \mathrm{~s}$ without shifting attention from the animal. The clock and on-going event are displayed on the recorder, making it possible to associate notes with times and events for later analysis. The resulting data are continuous sequences of behavioral and spatial transitions. Most observations began at or near the onset of activity in the morning, and continued into the early afternoon, or until the system memory ( $4 \mathrm{~K}$ bytes) was full and had to be transferred to cassette tapes.

The population tended to be active synchronously, and each day a different individual was chosen to be the focus of attention (i.e., the "focal animal," c.f. Altmann 1974). This individual was followed continuously with the aid of 8-power binoculars mounted on a tripod. An expanding neighborhood was examined by sequentially focusing on neighbors with overlapping ranges, and periodically re-examining individuals until a fairly stable pattern had been recorded (Getty, in press). Overlapping use-intensity patterns are reconstructed by superimposing individual patterns recorded on alternate days. I recorded nonfocal individuals whenever they co-occupied a quadrat or interacted otherwise with the focal animal. In the following discussion, "resident" refers to the particular "neighbor" that is currently the focus of attention. 


\section{REsults AND ANALYSES}

Of 150 different animals trapped on the study area in 1977, most were transients (defined as present $<2$ wk and trapped <six times). Most juveniles dispersed before their first capture. Trapping and casual observation indicated that chipmunk activity was concentrated along the marsh and the road. A total of 32 different animals received some focal attention, but only 12 different animals (one in both seasons) were observed adequately for analysis (c.f. Getty, in press). All subsequent analyses are limited to these individuals. They were established as groups of neighbors with overlapping ranges surrounded by areas with little activity.

Sexual differences in space utilization were relatively minor in this population, and in the species in general (Getty, in press); the sexes are therefore combined in subsequent analyses. Individual variability makes combining individuals more problematical than combining sexes.

Fig. 2 illustrates the typical, extensive overlap in chipmunk home ranges (c.f. Elliott 1978). The average distance from each center of activity to that of the nearest neighbor is $11 \pm 7 \mathrm{~m}$ in the summer, and $13 \pm$ $2 \mathrm{~m}$ in the fall. This is a relatively crowded group (c.f. Yahner 1978) with no exclusive core areas. In fact, these home ranges are used on average by the equivalent of 2.38 animals per range in the summer, and 2.03 in the fall. Given these conditions, do individuals "blunder" into each other at random (encounters are invariably hostile), or do they move in a fashion which reduces the likelihood of a hostile encounter?

\section{Encounters}

Crowding.-Hurlburt (1978) has pointed out the usefulness of Lloyd's (1967) index of "crowding" as a measure of the "probability of encounter." If two individuals lived entirely within one and the same quadrat, each would experience crowding equal to one, and would continuously "encounter" the other. The use intensity of a quadrat by an individual is equal to the fraction of that animal's total active time spent in that quadrat (Van Winkle 1975). If resident $i$ spends fraction $u_{i}(q)$ of its time in quadrat $q$, and neighbor $j$ spends $u_{j}(q)$ in $q$, then $i$ experiences crowding from $j$ in $q$ equal to: $u_{i}(q) \times u_{j}(q)$. Crowding within a quadrat is symmetrical for the case of two animals. If neighbor $k$ also uses $q$, and the probability of $i, j$ and $k$ all simultaneously occupying $q$ is vanishingly small (which is the case for these chipmunks), then resident $i$ experiences crowding in $q$ equal to $u_{i}(q)\left[u_{j}(q)+\right.$ $\left.u_{k}(q)\right]$. The overlapping use-intensity distributions resulted in residents being crowded, on the average, $3.50 \times 10^{-3}$ per quadrat in the summer $(n=173$ animal $\times$ quadrat combinations), and $5.98 \times 10^{-4}$ in the fall $(n=180)$. This is equivalent to the case of two animals uniformly superimposed on 16.90 quadrats in the summer, and 40.89 in the fall.

Co-occupation.-Bayes's rule (Salmon 1966) can be used to test whether neighbor movements are independent. If the probability of entering or remaining in a quadrat is independent of whether that quadrat is occupied by a neighbor, then the conditional status of the quadrat (occupied or not) is irrelevant. The expected fraction of an animal's time involving co-occupation with a neighbor in a given quadrat is equal to the crowding, as calculated above. However, if movements are timed such that there is a reduction in the frequency of encounters or the duration of co-occupation, then the conditional probability of co-occupation is reduced, and the observed value will be less than the crowding. Focal animals spent an average of $2.16 \times 10^{-5}$ of their time in co-occupation in the summer, and $1.37 \times 10^{-5}$ in the fall. This is an order of magnitude less than the expected crowding (statistical tests are presented below).

Co-occupation of quadrats is infrequent, and very brief when it does occur. Is the frequency less than expected from a model of independent movements? If quadrats are entered independently of whether they are currently occupied, then the probability that a quadrat which is entered is already occupied is simply the probability that it is occupied $\left(u_{j}(q)+u_{k}(q)+\right.$ ...). Only 7 of 1365 quadrat transitions in summer, and 24 of 1923 in the fall, resulted in co-occupation by neighbors. Since each animal $\times$ quadrat combination has a different probability of occupation by neighbors, observed and expected values must be compared quadrat by quadrat. Observed values are almost invariably less than expected. Nonparametric rank-sum and median tests on (observed-expected) values show that both frequency and total co-occupation are significantly less than expected from an independence model $(P<.0001)$. Chipmunks do not tolerate each other in close proximity (within $5 \times 5 \mathrm{~m}$ quadrats). The periphery of a resident's home range usually includes the center of a neighbor's. The neighbor will chase the resident if they encounter in the neighbor's core area, and the resident avoids encountering a neighbor in areas of the shared range where the neighbor dominates. The resulting nonrandom movements may be viewed as interference with space utilization, since they are indicative of temporal constraints on access. Do these temporal constraints actually result in reduced use intensity?

\section{Quadrat use intensity}

Home ranges average 24 quadrats in the summer, and 30 in the fall. No quadrats are occupied by a resident $>50 \%$ of the time, and most are occupied $<10 \%$ (Fig. 3). Since chipmunks cannot effectively monitor an entire home range from one location, most quadrats are unoccupied and unguarded most of the time. Before spatial competition can be assessed, other factors 
affecting use-intensity patterns must be considered. Within home ranges, the use intensity of a quadrat is expected to depend upon the distance of the quadrat from the center of activity, and the vegetational structure of the quadrat, as well as the activity of neighbors. Although experimental work is not presented here, irregular spatial distributions of these variables can be viewed as "natural experiments" (c.f. Sokal and Rohlf 1969).

Since quadrat patch structure is coded as an ordinal affiliation rather than a continuous variable, this factor must be incorporated into a regression model by the dummy variable technique (Kleinbaum and Kupper 1978). Linear regression analysis proved to be inappropriate, since residuals are systematically related to distance (Fig. 3), and not related to the other independent variables (c.f. Kleinbaum and Kupper 1978). Kleinbaum and Kupper suggest two alternative strategies in regression analysis when linear models are inappropriate: (a) try complex polynomial models, which may have no mechanistic relationship to reality but still develop a good fit if enough variables are incorporated, or (b) use theory and experience to develop less complex, and heuristically more interesting, models. A complicated model (11 parameters) which incorporates distance as a fourth-order polynomial, patch type by dummy variables, and a linear neighbor effect can explain 54\% of the variance in quadrat use intensity over both seasons. The patch and neighbor effects are consistent with the results based on the following model, which is relatively simple, has equivalent explanatory power, and is of some heuristic value (Getty 1981).

\section{Use-intensity model}

The model is based on a normal distribution, which has a long history of use in home range studies (Van Winkle 1975). My data (Fig. 3) and those of Elliott (1978, Figs. 8, 9) suggest that use intensity approximates a normal distribution over distance. Elliott explicitly models chipmunk home ranges as normal distributions (Elliott 1978, Fig. 12), and looks for the causes of departures from the normal distance effect. Conceptually, this is a form of "trend surface analysis," a common tool in geography for examining spatial patterns (Board 1967, Haggett et al. 1977). A variation of this technique was introduced to ecology as "response surface methodology" (Menke 1973). My model is a quantification of Elliott's (1978) qualitative approach with foundations in both geography and mammalogy.

It is hypothesized that use intensity of quadrat $q$ by individual $i$ is a function of the patch (microhabitat) quality of $q(p(q))$, distance from the central place (approximated by the center of activity) $d(q)$, a dispersion coefficient $\left(c_{0}\right)$, and the use of $q$ by neighbors multiplied by a coefficient of competitive impact $\left(c_{1}\right)$ :

$$
u_{i}(q)=p(q)\left[1-c_{1} u_{n}(q)\right] c_{0} \exp \left[-c_{0}^{2} d(q)^{2} \pi\right] .
$$

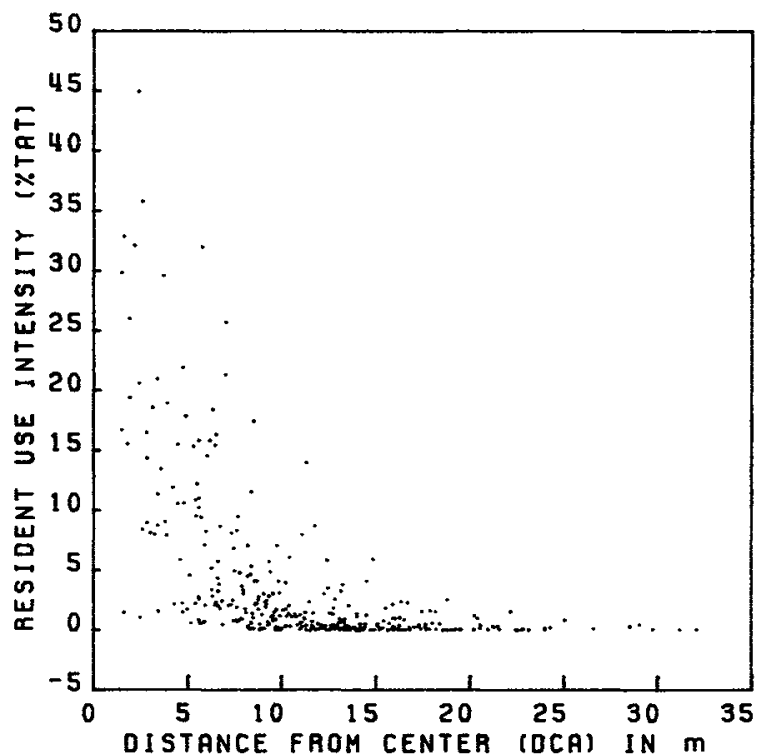

FIG. 3. Resident use intensity (percent of total activity time) as a function of distance from the center of activity (D.C.A.; combined seasons). $n=353$ animal-quadrat combinations.

If neither microhabitat heterogeneity nor competition are important, use intensity should fall symmetrically with distance in a bivariate normal pattern characterized by $c_{0}$. The value of $c_{1}$, and differences in $p(q)$ indicate the extent to which the smooth distance model is perturbed by neighbors and patches. Variables $u$, $d$, and $q$ are derived from the data and $p(q), c_{0}$, and $c_{1}$ are derived by a nonlinear, least-squares regression algorithm. Use intensities are in percentages rather than proportions, and distance is in metres.

The appropriateness of this normal "distance decay function" (c.f. Haggett et al. 1977) is indicated by the fact that regression of the data against distance alone, ignoring patches and neighbors, explains $60 \%$ of the variance in fall quadrat use intensity, and $52 \%$ overall. In the summer, when patch structure is important (see below), $46 \%$ of the variance is accounted for by the single distance variable. Incorporating all three factors, the results for the summer are as follows:

$$
u_{i}(q)=\left[\begin{array}{rr}
\text { type } & p(q) \\
1 & 174.5 \\
2 & - \\
3 & 164.8 \\
4 & 139.3 \\
5 & 263.4 \\
6 & 230.0 \\
7 & -
\end{array}\right]_{R^{2}=.52} n=173 \quad P<.001
$$

There is a relative preference for the marsn edge (patch type 5). Quadrats of this type are used more intensively than other types in the home ranges, and this is not a result of their location or abundance within 


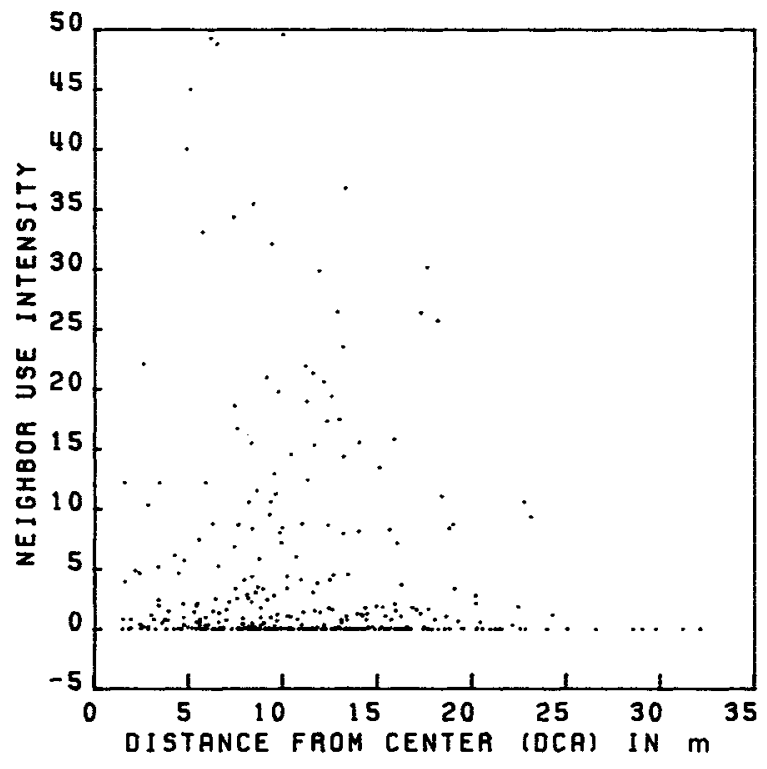

FIG. 4. Neighbor use intensity (percent of total activity time) as a function of distance from the resident's center of activity (D.C.A; combined seasons). $n=353$ animal-quadrat combinations.

home ranges. This patch type has the most complex vegetation structure: moist soil, well-developed herb and shrub strata, and many fallen trees. Quadrats in the dirt road (type 3 ) are used less than might be expected, given their location; the road cuts through the center of several home ranges. This area has depauperate vegetation, compacted soil (subterranean fungi are important in the diet), and lacks logs, brush, perches, etc. No significant differences in foraging success could be detected among patches (time eating/time foraging), but I suspect that open area offer less protection against predators (especially aerial predators). For the summer composite (average) animal, use intensity drops approximately $94 \%$ in the first $10 \mathrm{~m}$ from the center. At a given distance, a marsh-edge quadrat is used $60 \%$ more intensively than a road quadrat.

In the fall, consideration of patches and neighbors does not improve the simple distance-only model $\left(R^{2}=.59\right.$, essentially the same as the .60 for the distance-only model above). Patch coefficients differ less than in the summer for two reasons: the herbaceous stratum dies back, and most of the animals that I watched in the fall are not located along the sharp marsh edge vegetation gradient (Fig. 3).

The competition coefficient is never significantly different from zero ( $t$ tests on $c_{1}=-.026$ in the summer and +0.01 in the fall, c.f. Kleinbaum and Klupper 1978). Knowledge of neighbor use-intensity patterns adds no explanatory power to the model. Apparently neither resource depression nor territorial interference is sufficiently important to result in a negative relationship between resident and neighbor use intensity.

The finding that use intensity depends strongly upon distance from the center of activity is not a necessary consequence of the definition of the geometric center. Because home ranges usually extend beyond the center of neighboring home ranges, neighbor use intensity first increases, then decreases with distance (Fig. 4). Residual variation around the distance effect is not negatively related to neighbor use intensity. Residuals depend upon the specific distance model, of course, but none of the models examined reveal a significant negative competition effect.

\section{Discussion}

The various analyses of use-intensity patterns show that the location of quadrats with respect to the center of activity is a primary determinant of use intensity. The microhabitat structure of quadrats is important in the summer. Use intensity in the fall is very sensitive to the distribution of acorns on the ground, but data on this are not available for 1977 because few acorns fell that year. Home ranges are shared extensively; there are no exclusive core areas. There is conspicuous and effective fighting when neighbors encounter each other; however, individuals move about in a fashion that minimizes contact. Individual chipmunks engage in agonistic encounters at a rate of only 1.7 encounters $/ \mathrm{h}$ in the summer, and 3.2 encounters $/ \mathrm{h}$ in the fall. These rates, in conjunction with the crowding of home ranges, may have been unusually high (c.f. Ickes 1974). Higher rates are induced by experimental or natural concentrations of food, but this did not occur naturally during the study. Focal animals spent only $1.4 \pm 0.95 \%$ of their total active time in agonism in the summer, and $\mathbf{1 . 6} \pm \mathbf{0 . 6 1 \%}$ in the fall. Moreover, 87 of 101 encounters in the summer, and 85 of 115 in the fall were with dispersing or widely ranging nonneighbors.

The timing of movements can reduce the frequency of encounters, and therefore reduce the actual "crowding" experienced to a level below that which would occur if movements were independent. Several different processes could generate a nonrandom encounter pattern. One possibility, mutual avoidance, has been documented for nonterritorial groups of graycheeked mangabeys (Waser 1976). Leyhausen (1971) has suggested that avoidance is an important mechanism in mammalian territorial systems, allowing spatial time-sharing (i.e., use of the same space at different times). He suggests that neighbors establish and respect a timetable, while "newcomers" use sensory cues. Temporal partitioning of overlapping territories has been documented for a lizard population (Simon and Middendorf 1976), where neighbors are active at different times of day. It was suggested in this case that increased foraging efficiency results. Nonrandom movement and encounter patterns do not, however, necessarily result from mutual cooperation. Pikas, for instance, recognize territorial boundaries, but "timeshare" space by invading undetected while the resi- 
dent is not in the immediate vicinity (Kawamichi 1976). Since resident chipmunks often actively approach intruders, but not vice versa, it seems unlikely that this pattern represents cooperative mutual avoidance throughout overlapping ranges. Rather, the behavior suggests a unilateral avoidance of the resident near its core area with reciprocal deference in the intruder's core (c.f. Burt 1940 and Dunford 1970). Chipmunks clearly do not show mutual respect for territorial boundaries. They may, however, recognize neighbors, and be less likely to attack a neighbor than a nonneighbor in a given location. This "dear enemy phenomenon" was suggested by Fisher (1954), and has been documented for birds (Weeden and Falls 1959), fish (Thresher 1978), and mammals (Healy 1967). In fact, Healy (1967) suggested that the basic social unit for deermice is a group of territorial neighbors. Individual deermice are highly aggressive toward strangers, but mutual antagonism is reduced between established neighbors. This effectively regulates population density.

The combination of short quadrat visits with frequent returns (Getty, in press) reflects the fact that an individual does not deplete a quadrat's resources before moving on, possibly to patrol its range. An individual may, for instance, visit a raspberry patch, eat a few berries, leave, and periodically repeat the process over several days. Thus, although priority of access ("when") could affect how much resource is available to neighbors independently of how much access is available, this does not appear to be the case here. Even experimental concentrations of cachable resources (piles of nuts or trays of seeds), which are hauled away as fast as possible, are easily accessible to neighbors while the resident is in transit (c.f. Dunford 1979, T. Getty, personal observation). Priority of access in a limited access situation is frequently taken as a measure of social dominance. However, Syme et al. (1974) examined the literature on rodents in the laboratory and found that priority of access to limited food and water was poorly correlated with total access and growth performance.

Murie and Harris (1978) discuss the lack of exclusivity in mammalian territorial systems. Fisler (1969) suggested that territories (with defense), personal space dispersion (with avoidance), and hierarchies (with dominance roles) are all manifestations of continuous variation in two behavioral variables: aggressiveness and site attachment. Wolf (1978: Fig. 1) used a phase-plane diagram to express the continuity of these social systems as a function of three variables: site attachment (spatial orientation), resource orientation, and distance from a reference (self-orientation). The pattern described here includes aspects of all three of these classifications, in part because the tendencies to fight, avoid, and dominate conspecifics all vary with position in space.

It is not surprising that aggressive neighbors affect movement patterns, but if, as Case and Gilpin (1974) suggest, competitors "using common resources but at different times and places, avoid direct interactions, and therefore interference," then it is not clear whether avoidance implies interference or avoids interference. The concept that the proximate object of interference competition is access to space (Miller 1967) is not very useful, considering the temporal as well as quantitative nature of "access" and the resulting indeterminate relationship between total access to space and resource acquisition. This study illustrates a pattern of time-sharing, resulting from interference with the timing of access, but not the total quantity of access to space. Thus, interference at a point in time is not a sufficient condition for interference competition.

Because of the limited scope of this study, it cannot be asserted that resource competition is not occurring between these neighbors. However, competition was not evident from use-intensity patterns within established home ranges. Approximately $80 \%$ of encounters are with nonneighbors. Many of these are potential immigrants. This, in conjunction with the spacing of dens, suggests that chipmunk aggressive behavior successfully deters the establishment of new immigrants within crowded areas. Major episodes of mortality in this species occur during dispersal and during overwintering (Tryon and Snyder 1973), and winter survival depends on the caching of nuts in the fall rather than the accumulation of fat over the entire active season. It is reasonable to argue that when seasonal bottlenecks occur, competition and selection will be episodic, rather than continuous (Wiens 1977).

Elliott (1978) emphasizes the critical nature of establishment, compared to resource acquisition once a chipmunk is established. To the extent that territorial behavior limits population density, it also limits access to space at the establishment stage. Possibly because of this, established neighbors do not appear to be locked in relentless competition for access to space. It is still a matter of interpretation whether spatial time-sharing occurs in spite of interference with the timing of access to space, or because of encounteravoidance mechanisms.

\section{ACKNOWLEDGMENTS}

I thank the many people around Ann Arbor who helped with this project. Technical assistance was given by the staff of the University of Michigan Computing Center Shop, the Statistical Research Laboratory, Mark Green of the Economics Department, Pete Harley at the Botanical Gardens, and many others. Valuable advice was offered by my doctoral committee members: Brian Hazlett, Bobbi Low, Phil Myers, and Beverly Rathcke, and other friends in the Department of Ecology and Evolutionary Biology, including Peter Grant, Don Tinkle, Chris Meacham, Neal Oden, Diane DeSteven, Mike Huston, Pat Dillon, and others. Christine Baumann helped with all stages of this project. This work was done in partial fulfillment of the requirements for the degree of Doctor of Philosophy, the University of Michigan, 1980. The work was supported by the Biology Division, the E. S. 
George Reserve of The Museum of Zoology, and The Rackham School of Graduate Study.

\section{Literature Cited}

Altmann, J. 1974. Observational study of behavior: sampling methods. Behavior 49:227-266.

Board, C. 1967. Maps as models. Pages 671-719 in R. J. Chorley and P. Haggett, editors. Models in geography. Methuen, London, England.

Burt, W. H. 1940. Territorial behavior and populations of some small mammals in southern Michigan. Miscellaneous Publication 45, University of Michigan Museum of Zoology, Ann Arbor, Michigan, USA.

Case, T. J., and M. E. Gilpin. 1974. Interference competition and niche theory. Proceedings of the National Academy of Sciences 71:3073-3077.

DeGhett, V. J. 1978. Hierarchical cluster analysis. Pages 115-144 in P. W. Colgan, editor. Quantitative ethology. John Wiley and Sons, New York, New York, USA.

Dunford, C. 1970 . Behavioral aspects of social organization in the chipmunk, Tamias striatus. Behavior 36:215-231.

Elliott, L. 1978. Social behavior and foraging ecology of the eastern chipmunk (Tamias striatus) in the Adirondack Mountains. Smithsonian Contributions to Zoology 265:1107.

Fisher, J. 1954. Evolution and bird sociality. Pages 71-83 in J. Huxley, A. C. Hardy, and E. B. Ford, editors. Evolution as a process. George Allen and Unwin, London, England.

Fisler, G. F. 1969. Mammalian social systems. Los Angeles County Museum Contributions in Science 169:1-32.

Getty, T. 1981. Analysis of central-place space-use patterns: the elastic disc revisited. Ecology 62:907-914.

- In press. Structure and dynamics of chipmunk home range. Journal of Mammalogy.

Haggett, P. A., A. D. Cliff, and A. Frey. 1977. Locational analysis in human geography. Edward Arnold, London, England.

Healy, M. C. 1967. Aggression and self-regulation of population size in deermice. Ecology 48:377-392.

Hurlburt, S. H. 1978. The measurement of niche overlap and some relatives. Ecology 59:67-77.

Kawamichi, T. 1976. Hay territory and dominance rank of pikas (Ochotona princeps). Journal of Mammalogy 57:133148.

Kleinbaum, D. G., and L. L. Kupper. 1978. Applied regression analysis and other multivariate methods. Duxbury Press, North Scituate, Massachusetts, USA.

Leyhausen, P. 1971. Dominance and territoriality as complemented in mammalian social structure. Pages $22-33$ in A. H. Esser, editor. Behavior and environment. Plenum, New York, New York, USA.

Lloyd, M. 1967. "Mean crowding." Journal of Animal Ecology $36: 1-30$.
Menke, W. W. 1973. Response surface methodology applications to biological data from field measurements. Ecology 54:920-923.

Miller, R. 1967. Competition and species diversity. Brookhaven Symposium on Biology 22:63-70.

Murie, J. O., and M. A. Harris. 1978. Territoriality and dominance in male Columbian ground squirrels (Spermophilus columbianus). Canadian Journal of Zoology 56:2402-2412.

Salmon, W. C. 1966. The foundations of scientific inference. University of Pittsburgh Press, Pittsburgh, Pennsylvania, USA.

Simon, C. A., and G. A. Middendorf. 1976. Resource partitioning by an iguanid lizard: temporal and microhabitat aspects. Ecology 57:1317-1320.

Sokal, R. R. and F. J. Rohlf. 1969. Biometry. Freeman, San Francisco, California, USA.

Syme, G. J., J. S. Pollard, L. A. Syme, and R. M. Reid. 1974. An analysis of the limited access measure of social dominance in rats. Animal Behaviour 22:486-500.

Thresher, R. E. 1978. The role of individual recognition in the territorial behaviour of the Threespot Damselfish $\mathbf{E u}$ pomacentrus planifrons. Marine Behaviour and Physiology 6:83-93.

Tinnin, R. O. 1972. Interference or competition? American Naturalist 106:672-675.

Tryon, C. A., and D. P. Snyder. 1973. Biology of the eastern chipmunk, Tamias striatus: life tables, age distributions and trends in population numbers. Journal of Mammalogy 26: $115-168$.

Van Winkle, W. 1975. Comparison of several probabilistic home-range models. Journal of Wildlife Management 39:118-123.

Waser, P. M. 1976. Cercocebus albigena: site attachment, avoidance and intergroup spacing. American Naturalist 110:911-935.

Weeden, J. S., and J. B. Falls. 1959. Differential responses of male ovenbirds to recorded songs of neighbors and more distant individuals. Auk 76:343-351.

Wiens, J. A. 1977. On competition and variable environments. American Scientist 65:590-597.

Wilson, E. O. 1975. Sociobiology. Belknap, Cambridge, Massachusetts, USA.

Wolf, L. L. 1978. Aggressive social organization in nectarivorous birds. American Zoologist 18:765-778.

Yahner, R. H. 1977. Activity lull of Tamias striatus during the summer in southeast Ohio. Ohio Journal of Science 77:143-145.

Zenker, J. 1978. A vegetational analysis of an oak-hickory woods. Honors Thesis. Kalamazoo College, Kalamazoo, Michigan, USA. 